\title{
Positive correlation between symptoms and circulating motilin, pancreatic polypeptide and gastrin concentrations in functional bowel disorders
}

\author{
D M PRESTON, T E ADRIAN, N D CHRISTOFIDES, J E LENNARD-JONES, \\ AND S R BLOOM
}

From St Mark's Hospital and Royal Postgraduate Medical School, London

SUMMARY Motilin, pancreatic polypeptide and gastrin blood concentrations in response to drinking water have been studied in 40 patients with functional bowel disease and compared with results in two groups of healthy control subjects. Patients with slow transit constipation and idiopathic megacolon showed impaired motilin release. Pancreatic polypeptide release was reduced in patients with slow transit constipation, but increased in those with functional diarrhoea. Gastrin release was impaired in all groups complaining of chronic constipation. Circulating motilin, pancreatic polypeptide and gastrin concentrations appear to bear some relationship to intestinal transit time in patients with functional bowel disorders.

The functional bowel disorders present a confusing clinical picture to the gastroenterologist. It has been suggested that abnormal concentrations of gut regulatory peptides, or an abnormal response to physiological levels may be responsible for some of the motility disturbances in these patients. ${ }^{1}$ Because different nutrients have a varied effect on peptide release, we have used an oral water load as a simple and reproducible stimulus. This stimulus has been shown in normal subjects to result in a significant rise in circulating motilin levels, as well as an increase in the concentrations of pancreatic polypeptide and gastrin. ${ }^{2}$ The main purpose of the present study was to examine release of these peptides in patients complaining of constipation and diarrhoea.

Patients with functional bowel disease present with many different symptoms which tend to fluctuate from day to day so that a study on one day may not be representative. In this study, we have attempted to define groups of patients with a consistent pattern of symptoms, so as to maximise any difference between the groups. It is possible to define a subgroup who present with chronic diarrhoea. Those patients who present with a complaint of chronic constipation can be divided into three subgroups. One group have a prolonged

Address for correspondence: Professor J E Lennard-Jones. St Mark's Hospital. City Road. London EC1V 2PS.

Received for publication 21 November 1984 gut transit time but a normal barium enema (idiopathic slow transit constipation), another group have an enlarged colon (idiopathic megacolon) and there are some with a normal transit rate and normal barium enema. In the latter subgroup, abdominal pain is usually a major feature and the symptom pattern is included within the wide group of patients with the painful irritable bowel syndrome. The aetiology of all these disorders is unknown.

\section{Methods}

SELECTION OF PATIENTS AND CONTROL SUBJECTS Four groups of patients and two groups of control subjects were studied. All gave informed consent after the nature and purpose of the investigations had been explained.

\section{Slow transit constipation(12)}

This group comprised 12 women with severe constipation. They had been symptomatic for an average of 14 years before the study. All had doublecontrast barium enema by a standard technique which showed a colon of normal size. ${ }^{3}$ Each patient showed evidence of delayed intestinal transit in that at least 16 radio-opaque markers remained in the colon five days after administration. ${ }^{4}$ The mean number of bowel actions per week in this group was $0 \cdot 5$. Mean age was 27 years and mean percentage ideal body weight $97 \pm 2 \%$. 
Idiopathic megacolon (10)

This group comprised seven women and three men who were clinically constipated with evidence of colonic and rectal distension on barium enema as judged by measurement of rectal area and colonic width. ${ }^{3}$ Hirschsprung's disease had been excluded by the presence of a normal rectosphincteric reflex. All had rectal obstipation at the time of study. The mean number of bowel actions per week was $3 \cdot 5$, mean age was 23 years and mean percentage ideal body weight $95 \pm 3 \%$.

\section{Irritable bowel syndrome with pain (nine)}

This group comprised eight women and one man who complained of severe abdominal pain and constipation. None experienced any episodes of diarrhoea. Barium enema and transit studies were normal in all cases. The mean number of bowel actions per week was $4 \cdot 3$, mean age was 45 years and mean percentage ideal body weight $102 \pm 4 \%$.

\section{Functional diarrhoea (nine)}

This group comprised six women and three men who had been investigated for chronic diarrhoea for which no cause had been found on extensive radiological, endoscopic and laboratory investigation. The mean age was 46 years and mean percentage ideal body weight $112 \pm 11 \%$.

\section{Control subjects}

Control studies were carried out on volunteers from medical and ancillary hospital staff. None had sought medical advice for any bowel complaint and reported bowel function to direct questioning as 'normal'. The exact frequency of their bowel actions was not sought before the study to avoid bias in selection. Subsequent questioning showed that the mean number of bowel actions per week in this group was six. Because all the subjects with slow transit constipation were women, two control groups were prepared as follows: group A comprised 12 women, mean age 29 years and mean percentage ideal body weight $98 \pm 4 \%$. This group was compared with the patients with slow transit constipation. Group B comprised nine women and three men, mean age 42 years and mean percentage ideal body weight $101 \pm 4 \%$. This group was compared with the patients with irritable bowel and idiopathic megacolon.

\section{EXPERIMENTAL DESIGN}

All drugs were stopped 24 hours before the test. The stimulus to release of gut hormones was $10 \mathrm{ml} / \mathrm{kg}$ of tap water drunk within 5 minutes after a 12 hour fast. Blood samples were taken at $-10,0,+10$, $+20,+40$, and +60 minutes from ingestion of water and placed in heparinised tubes containing $400 \mathrm{KI}$ units $/ \mathrm{ml}$ of aprotinin. After separation, the plasma was stored at $-20^{\circ} \mathrm{C}$ until assay. Hormone radioimmunoassays were carried out by methods previously described using antisera raised to synthetic human gastrin 1, natural human pancreatic polypep; tide and natural porcine motilin. ${ }^{5}$ The gastrin assay sees both sulphated and non-sulphated forms of G-17 and G-34 and shows less than $2 \%$ cross reaction with CCK-8 and CCK-33. Motilin and pancreatic polypeptide antisera exhibit no cross reaction to other known regulatory peptides. The assays could detect the following plasma changes with $95 \%$ confidence: gastrin $1 \mathrm{pmol} / \mathrm{l}$, pancreatic polypeptide $4 \mathrm{pmol} / 1$, and motilin $3 \mathrm{pmol} / 1$.

Statistical significance was assessed by use of the Student's $t$ test, or the Wilcoxon's test. The integrated incremental response was calculated as the area under the curve to give an approximation of the total release of each hormone over the hour, less the mean basal value. The total integrated response was calculated in the same way to express the total release of each hormone over the hour. The total integrated response was felt to be a more appropriate measure of hormone release between groups where the fasting concentrations were widely different.

\section{Results}

Basal (fasting) concentrations, peak rise after the water load, the integrated incremental response (IIR) and total integrated response (TIR) of motilin, pancreatic polypeptide and gastrin over one hour are shown in Tables $1-3$. The mean rise for these hormones for patients with functional diarrhoea or slow transit constipation are illustrated in Figures 1-3.

\section{IRRITABLE BOWEL SYNDROME/PAIN \\ (a) Motilin}

No significant changes were seen.

\section{(b) Pancreatic polypeptide}

No significant changes were seen.

\section{(c) Gastrin}

Basal concentrations of gastrin tended to be reduced compared with controls. After drinking, there was a significant reduction in the peak rise $(\mathrm{p}<0.05)$ and in the total integrated response $(p<0 \cdot 02)$.

\section{FUNCTIONAL DIARRHOEA}

(a) Motilin

Fasting concentrations of motilin were raised $(p<0.05)$. The subsequent rise after drinking was 
Table 1 Plasma motilin concentrations after drinking water $(10 \mathrm{ml} / \mathrm{kg})$ in control subjects and the four patient groups

\begin{tabular}{lllll}
\hline & Basal & Peak rise & IIR & TIR \\
\hline Controls (a) & $32 \cdot 0 \pm 6 \cdot 9$ & $38 \cdot 4 \pm 6 \cdot 0$ & $1 \cdot 38 \pm 0 \cdot 2$ & $3 \cdot 30 \pm 0 \cdot 56$ \\
Constipation & $34 \cdot 9 \pm 5 \cdot 4$ & $13 \cdot 25 \pm 4 \cdot 6 \ddagger$ & $0 \cdot 29 \pm 0 \cdot 1 \ddagger$ & $2 \cdot 32 \pm 0 \cdot 41$ \\
Controls (b) & $39 \cdot 4 \pm 8 \cdot 3$ & $41 \cdot 2 \pm 5 \cdot 0$ & $1 \cdot 48 \pm 0 \cdot 2$ & $3 \cdot 84 \pm 0 \cdot 6$ \\
Megacolon & $47 \cdot 8 \pm 4 \cdot 5$ & $16 \cdot 2 \pm 8 \cdot 4 \dagger$ & $0 \cdot 38 \pm 0 \cdot 4 \ddagger$ & $3 \cdot 25 \pm 0 \cdot 37$ \\
IBS/pain & $64 \cdot 3 \pm 13 \cdot 9$ & $30 \cdot 0 \pm 8 \cdot 0$ & $0 \cdot 98 \pm 0 \cdot 2$ & $4 \cdot 55 \pm 0 \cdot 78$ \\
Diarrhoea & $83 \cdot 4 \pm 15 \cdot 1^{*}$ & $33 \cdot 0 \pm 10 \cdot 0$ & $1 \cdot 13 \pm 0 \cdot 4$ & $6 \cdot 13 \pm 0 \cdot 83$ \\
\hline
\end{tabular}

$* p<0.05 ;+p<0 \cdot 02 ; \ddagger p<0 \cdot 01$. Basal and peak hormone concentrations given as $p m o l / 1(m e a n \pm S E M)$. Integrated incremental response (IIR) and total integrated response (TIR) in nmol/l over 60 minutes. $p$ values $v s$ controls.

not, however, significantly different from control subjects.

\section{(b) Pancreatic polypeptide}

Both the fasting concentrations of pancreatic polypeptide and the subsequent rise after drinking were significantly increased $(p<0.02)$. The integrated incremental response and total integrated response were also markedly increased $(p<0.01)$.

\section{(c) Gastrin}

No significant changes were seen.

\section{SLOW TRANSIT CONSTIPATION}

\section{(a) Motilin}

Fasting concentrations of motilin were normal but the peak rise and integrated incremental response were significantly reduced $(p<0.01)$.

(b) Pancreatic polypeptide

Fasting concentrations of pancreatic polypeptide were normal but the peak rise and integrated incremental response after the drink were reduced $(\mathrm{p}<0.05)$.

\section{(c) Gastrin}

Fasting concentration of gastrin and the peak rise after a drink were significantly reduced compared with control subjects $(p<0.05)$. There was also a marked decrease in the total integrated response $(\mathrm{p}<0 \cdot 01)$.

\section{IDIOPATHIC MEGACOLON}

\section{(a) Motilin}

Fasting motilin concentrations were normal. Both the peak rise and integrated incremental response after drinking, however, were reduced $(p<0.02$ and $\mathrm{p}<0 \cdot 01)$.

\section{(b) Pancreatic polypeptide}

No significant changes were seen.

\section{(c) Gastrin}

Concentrations of gastrin tended to be lower than controls throughout but the only significant difference was at +20 minutes (controls $14.0 \mathrm{pmol} / \mathrm{l} \pm 2 \cdot 1$ SEM; megacolon $4.5 \pm 2 \cdot 6 ; \mathrm{p}<0 \cdot 05)$. The total integrated response was, however, significantly reduced $(\mathrm{p}<0.01$.

\section{Discussion}

In a previous study of a group of patients with the irritable bowel syndrome, Besterman et al examined the effect of a test breakfast on circulating concentrations of gut regulatory peptides. ${ }^{6}$ Looking at the patients as a group, there were no significant

Table 2 Plasma pancreatic polypeptide concentrations after drinking water $(10 \mathrm{ml} / \mathrm{kg})$ in control subjects and the four patient groups

\begin{tabular}{|c|c|c|c|c|}
\hline & Basal & Peak rise & $I I R$ & $T I R$ \\
\hline $\begin{array}{l}\text { Controls (a) } \\
\text { Constipation }\end{array}$ & $\begin{array}{l}39 \cdot 8 \pm 10 \cdot 0 \\
25 \cdot 8 \pm 5 \cdot 1\end{array}$ & $\begin{array}{r}109 \cdot 7 \pm 37 \cdot 4 \\
40 \cdot 7 \pm 13 \cdot 0\end{array}$ & $\begin{array}{l}3 \cdot 57 \pm 1 \cdot 3 \\
1 \cdot 40 \pm 0 \cdot 4^{*}\end{array}$ & $\begin{array}{l}6 \cdot 11 \pm 1 \cdot 8 \\
2 \cdot 94 \pm 0 \cdot 6 \ddagger\end{array}$ \\
\hline $\begin{array}{l}\text { Controls (b) } \\
\text { Megacolon } \\
\text { IBS/pain } \\
\text { Diarrhoea }\end{array}$ & $\begin{array}{l}37 \cdot 7 \pm 10 \cdot 1 \\
36 \cdot 2 \pm 11 \cdot 1 \\
46 \cdot 7 \pm 10 \cdot 4 \\
75 \cdot 1 \pm 17 \cdot 0 \dagger\end{array}$ & $\begin{array}{c}111 \cdot 4 \pm 36 \cdot 7 \\
77 \cdot 2 \pm 42 \cdot 1 \\
99 \cdot 1 \pm 41 \cdot 9 \\
228 \cdot 0 \pm 49 \cdot 7+\end{array}$ & $\begin{array}{l}3 \cdot 84 \pm 1 \cdot 4 \\
2 \cdot 40 \pm 1 \cdot 1 \\
4 \cdot 22 \pm 1 \cdot 4 \\
8 \cdot 35 \pm 1 \cdot 9 \ddagger\end{array}$ & $\begin{array}{c}6 \cdot 12 \pm 1 \cdot 9 \\
5 \cdot 61 \pm 1 \cdot 7 \\
6 \cdot 38 \pm 1 \cdot 9 \\
12 \cdot 89 \pm 2 \cdot 0 \ddagger\end{array}$ \\
\hline
\end{tabular}

* $\mathrm{p}<0.05 ; \dagger \mathrm{p}<0.02 ; \ddagger \mathrm{p}<0.01$. Basal and peak hormone concentrations given as pmol/l (mean $\pm \mathrm{SEM})$. Integrated incremental response (IIR) and total integrated response (TIR) in nmol/l over 60 minutes. $p$ values $v s$ controls. 
Table 3 Plasma gastrin concentrations after drinking water $(10 \mathrm{ml} / \mathrm{kg})$ in control subjects and the four patient groups

\begin{tabular}{lcccc}
\hline & Basal & Peak rise & IIR & $T I R$ \\
\hline Controls (a) & $7 \cdot 5 \pm 2 \cdot 2$ & $11 \cdot 5 \pm 2 \cdot 6$ & $220 \pm 87$ & $699 \pm 113$ \\
Constipation & $2 \cdot 5 \pm 0 \cdot 6^{*}$ & $5 \cdot 6 \pm 1 \cdot 8^{*}$ & $88 \pm 48$ & $247 \pm 47 \ddagger$ \\
Controls (b) & $8 \cdot 3 \pm 2 \cdot 3$ & $12 \cdot 0 \pm 3 \cdot 9$ & $228 \pm 97$ & $729 \pm 148$ \\
Megacolon & $4 \cdot 12 \pm 0 \cdot 5$ & $5 \cdot 72 \pm 1 \cdot 9$ & $69 \pm 34$ & $323 \pm 39 \dagger$ \\
IBS/pain & $4 \cdot 7 \pm 0 \cdot 7$ & $4 \cdot 4 \pm 1 \cdot 5^{*}$ & $113 \pm 40$ & $297 \pm 63+$ \\
Diarrhoea & $10 \cdot 5 \pm 6 \cdot 6$ & $11 \cdot 5 \pm 4 \cdot 8$ & $211 \pm 69$ & $843 \pm 44$ \\
\hline
\end{tabular}

${ }^{*} \mathrm{p}<0.05 ; \dagger \mathrm{p}<0.02 ; \ddagger \mathrm{p}<0.01$. Basal and peak hormone concentrations given as $\mathrm{pmol} / \mathrm{l}(\mathrm{mean} \pm \mathrm{SEM})$. Integrated incremental response (IIR) and total integrated response (TIR) in $\mathrm{nmol} / \mathrm{l}$ over 60 minutes. $\mathrm{p}$ values $v s$ controls.

changes, but when divided into subgroups, based on the predominant symptoms of pain, diarrhoea or constipation, some changes were found in the release of gastric inhibitory polypeptide and neurotensin. They concluded that as these abnormalities were minor, it was unlikely that the fasting or postprandial response of gut hormones were of any significance in the pathophysiology of the irritable bowel syndrome. In the present study, we have chosen groups of patients with a consistent pattern of symptoms and have used a different stimulus. An attempt has also been made to define subgroups of patients complaining of chronic constipation using objective tests.

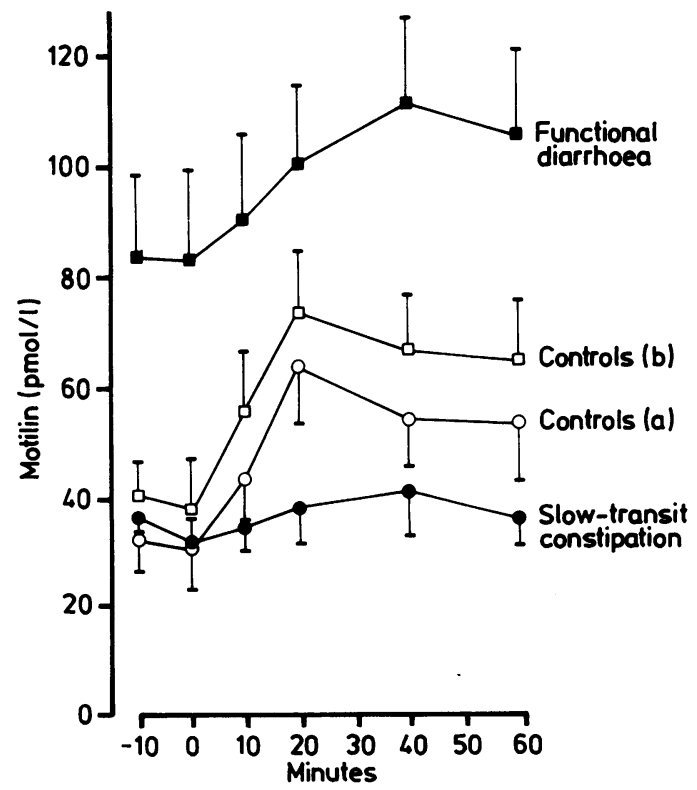

Fig. 1 Plasma concentrations of motilin (mean $\pm S E)$ before and after an oral water load $(10 \mathrm{ml} / \mathrm{kg})$ in control subjects, patients with functional diarrhoea and idiopathic slow transit constipation.
In both groups with idiopathic constipation, there was a marked reduction in motilin release. This finding is interesting as studies in animals have suggested a relationship between circulating motilin concentrations and the peristaltic activity of the gut. $^{7}$ Lower motilin concentrations have recently been reported during pregnancy when there is reduced smooth muscle tone in the gut and constipation is a common problem. ${ }^{8}$ It has also been shown that colonic pressure activity in humans can be stimulated by infusion of motilin. ${ }^{9}$ In the group with chronic diarrhoea, there was a significant elevation of fasting motilin concentrations and similar changes have previously been reported in patients with

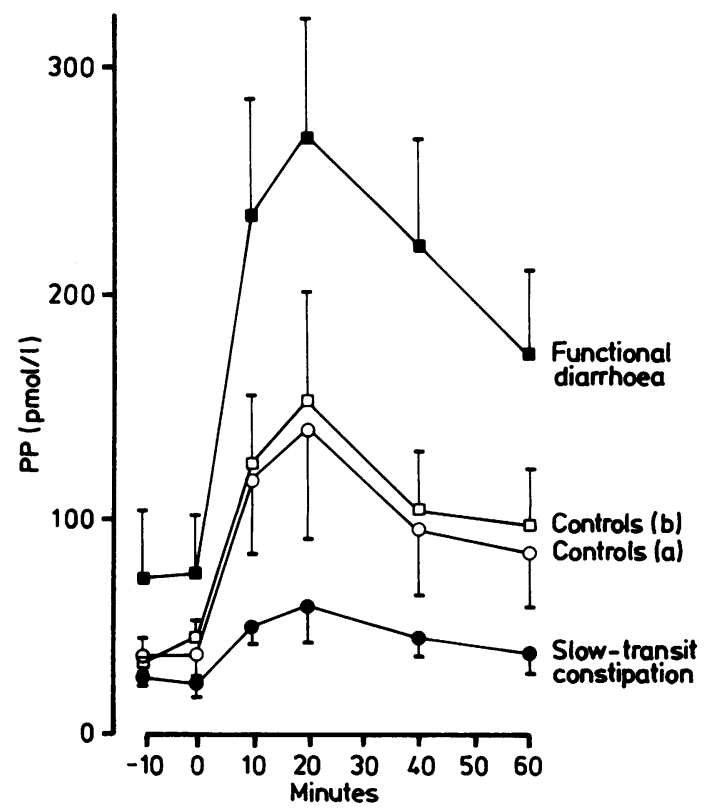

Fig. 2 Plasma concentrations of pancreatic polypeptide (mean $\pm S E$ ) before and after an oral water load $(10 \mathrm{ml} / \mathrm{kg}$ ) in control subjects, patients with functional diarrhoea and idiopathic slow transit constipation. 


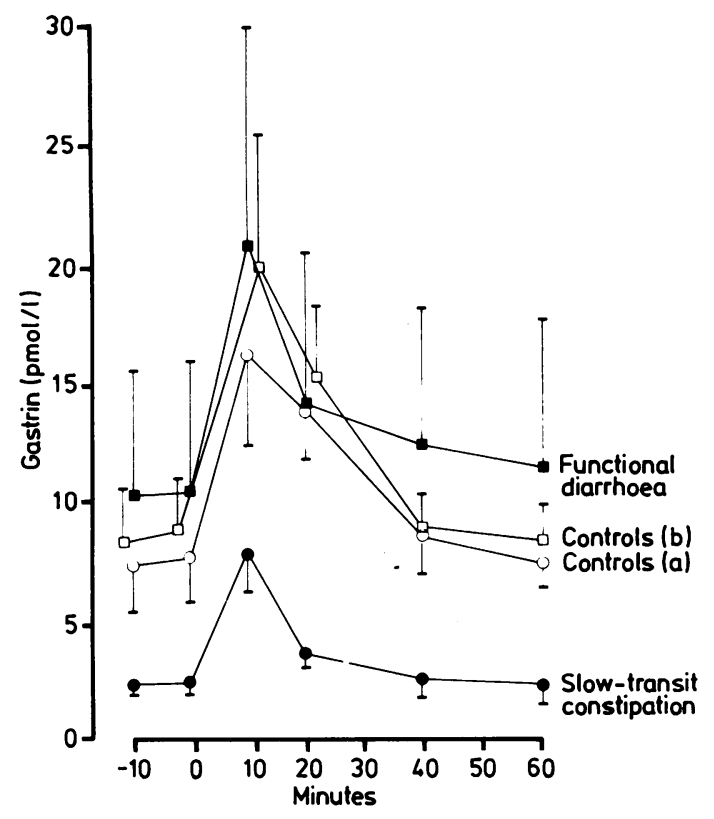

Fig. 3 Plasma concentrations of gastrin (mean $\pm S E$ ) before and after an oral water load $(10 \mathrm{ml} / \mathrm{kg})$ in control subjects, patients with functional diarrhoea and idiopathic slow transit constipation.

diarrhoea from a variety of causes. ${ }^{10-13}$ Actions of motilin include acceleration of gastric emptying ${ }^{14}$ and initiation of the interdigestive motor complex, ${ }^{15}$ factors which may be important in patients with chronic diarrhoea.

The total integrated response of pancreatic polypeptide was significantly reduced in patients with slow transit constipation and increased in those with chronic diarrhoea. The impaired release in patients with constipation is a new finding and its significance is not clear. No studies have yet been done to investigate the possible relationship between pancreatic polypeptide release and colonic motility in man. Studies in dogs, however, have shown that very high doses of bovine polypeptide given intravenously may lead to defaecation and slow intravenous infusion resulted in an increase followed by a decrease in the motility of the whole gut. ${ }^{16}$ In the previous study, pancreatic polypeptide concentrations were higher at rest in patients with the irritable bowel syndrome ${ }^{6}$ and our study confirms this finding in those who complain of chronic diarrhoea.

Gastrin release was impaired in all groups with constipation, including those who complained principally of abdominal pain and whose total intestinal transit time was normal. It is of interest that concentrations of a hormone principally released from the stomach should be abnormal in patients with what was thought to be primarily a colonic problem. Some of the motor activity of the colon correlates with the rise in gastrin concentrations after a meal and it has been suggested that gastrin plays a part in the so called gastrocolic response. ${ }^{17} \mathrm{It}$ has also been suggested that an abnormal response to circulating gastrin concentrations may be responsible for the symptom of abdominal pain in some patients with the irritable bowel syndrome. ${ }^{1}$ The present studies show that concentrations are low in patients who complain principally of pain and constipation and it is unlikely, therefore, that circulating gastrin plays a part in the production of their symptoms.

The complexity of the functional bowel disorders make it likely that there are many factors involved in the production of these patients' symptoms. There is no obvious explanation for the impairment of gastrin, motilin, and pancreatic polypeptide release in patients with slow transit constipation. The concentrations may be affected by another humoral agent which has not been examined (or discovered). It is possible that peptide containing cells in the gut wall are damaged by chronic laxative use. Damage to the intramural ganglion cells is known to occur after prolonged use of anthraquinone-type laxatives. ${ }^{18}$ Another possible explanation is that circulating peptides are depressed as a secondary phenomenon in response to abnormal gut motor activity of unknown cause. It may be relevant that a recent study has shown that gastrin secretion in man can be inhibited by colonic infusion of glucose, mannitol, and saline. ${ }^{19}$ The mechanism of such inhibition may be humoral or neural and somatostatin and enteroglucagon are candidate peptides.

Our results suggest that division of patients with functional bowel disease into different categories may lead to a better understanding of the pathophysiology of these disorders. In particular, patients with slow transit constipation or diarrhoea appear to have a different hormone response from those with the irritable bowel syndrome who have normal whole gut transit time. It is unlikely that abnormal circulating concentrations of known gut hormones play an important part in the production of symptoms in patients with the irritable bowel syndrome whose transit time is normal and who complain principally of severe abdominal pain.

\section{References}

1 Harvey RF. The irritable bowel syndrome - Part III: hormonal influences. Clin Gastroenterol 1977; 6: 
631-41.

2 Christofides ND, Sarson DL, Albuquerque RH, Adrian TE, Ghatei MA, Modlin IM. Release of gastrointestinal hormones following an oral water load. Experientia 1979; 35: 1521-2.

3 Preston DM, Lennard-Jones JE, Thomas BM. Towards a radiologic definition of idiopathic megacolon. Gastrointest Radiol 1985; 10: 167-9.

4 Hinton JM, Lennard-Jones JE, Young AC. A new method for studying gut transit times using radioopaque markers. Gut 1969; 10: 842-7.

5 Bloom SR, Long RG (ed). Radioimmunoassay of gut regulatory peptides. London: W B Saunders Co, 1982.

6 Besterman HS, Sarson DL, Rambaud JC, Stewart JS, Guerin S, Bloom SR. Gut hormone response in the irritable bowel syndrome. Digestion 1981; 21: 219-24.

7 Itoh Z. Effect of motilin on gastrointestinal tract motility. In: Bloom SR, ed. Gut hormones. London: Churchill Livingstone, 1981: 280-9.

8 Christofides ND, Ghatei MA, Bloom SR, Borberg C, Gillmer MDG. Decreased plasma motilin concentrations in pregnancy. $\mathrm{Br}$ Med J 1982; 285: 1453-4.

9 Rennie JA, Christofides ND, Mitchenere P, Johnson AG, Bloom SR. Motilin and human colonic activity. [Abstract] Gastroenterology 1980; 78: A1243.

10 Besterman HS, Bloom SR, Sarson DL et al. Gut hormone profile in coeliac disease. Lancet 1978; 1: 785-8.
11 Besterman HS, Cook GC, Sarson DL et al. Gut hormones in tropical malabsorption. Br Med J 1979; 2: 1252-5.

12 Besterman HS, Christofides ND, Welsby PD, Adrian TE, Sarson DL, Bloom SR. Gut hormones in acute diarrhoea. Gut 1983; 24: 665-71.

13 Besterman HS, Adrian TE, Mallinson CN et al. Gut hormones release after intestinal resection. Gut 1982; 23: 854-61.

14 Christofides ND, Long RG, Fitzpatrick ML, McGregor GP, Bloom SR. Effect of motilin on the gastric emptying of glucose and fat in humans. Gastroenterology 1981; 80: 456-60.

15 Vantrappen G, Janssens J, Peeters TL, Bloom SR, Christofides ND, Hellemans J. Motilin and the interdigestive migrating motor complex in man. Dig Dis Sci 1979; 24: 497-500.

16 Lin TM, Chance RE. Spectrum of gastrointestinal actions of bovine PP. In: Bloom SR, ed. Gut hormones. London: Churchill Livingstone, 1978: 242-6.

17 Kirwan WO, Smith AN. Post prandial changes in colonic motility related to serum gastrin levels. Scand $J$ Gastroenterol 1976; 11: 145-9.

18 Smith B. Effect of irritant purgatives on the myenteric plexus in man and the mouse. Gut 1968; 9: 139-43.

19 Jian R, Besterman HS, Sarson DL et al. Colonic inhibition of gastric secretion in man. Dig Dis Sci 1981; 26: 195-201. 